\title{
Hemorrhagic Cerebrovascular Accident
}

National Cancer Institute

\section{Source}

National Cancer Institute. Hemorrhagic Cerebrovascular Accident. NCI Thesaurus. Code C95803.

An acute episode of focal or global cerebral or spinal dysfunction caused by intraparenchymal, intraventricular, or subarachnoid hemorrhage. 